\title{
Discussion on the business performance of life insurance industries in Taiwan and Mainland China-Application of Metafrontier model
}

\author{
James C. Hao \\ (Department of Insurance, Tamkang University, Tamsui 251, Taiwan)
}

\begin{abstract}
When using the Data Development Analysis method for analyzing the efficiency of different firms, it is common to put all similar DMU together for measurement in order to figure out the efficiency values of various DMU. However, such an analysis may easily neglect the source property of an individual DMU, meaning that the differences among various DMUs derive from different environmental backgrounds, e.g. environment variables such as economic civilization, laws and regulations, and political backgrounds. Applying the Metafrontier model can overcome the barriers resulting from the environment variables, and it can analyze and measure the differences among various DMUs which have different source properties. It can also be used for measuring the difference between each group of DMU and all DMUs. Therefore, this study adopts the DEA method, assuming variable returns to scale to evaluate and comparatively analyze the business performance of life insurance industries in Taiwan and Mainland China based on "BBC input orientation". When evaluating the business performance, the operating management echelon is affected by uncontrollable external environment variables. Thus, this study applies the Four-Stage Data Envelopment Analysis to discuss the impact of environment variables on business performance and re-measures the business efficiency of life insurance industries in Taiwan and Mainland China after adjusting the input variables. The demonstration period adopted by this study is from 2003 to 2005, and the research subject comprises 43 companies in Taiwan and Mainland China, among which, there are 19 companies in Taiwan and 24 companies in Mainland China, and there are 129 sets of sample data. It is assumed that the discount rate is $\gamma$ ( $\gamma$ is set as $3 \%$ in this paper), and figured out the change of each life insurance company in technical efficiency in the inter-period accumulative years from 2003 to 2005.
\end{abstract}

Key words: Metafrontier model; Four-Stage Data Envelopment Analysis; environment variables

\section{Research motives and purposes}

In recent years, the economic environment in Taiwan and overseas has changed significantly. The Asia-Pacific region's economies have grown rapidly, and cross-straits business between Taiwan and Mainland China has become close, changing greatly the insurance and financial environment. Following the reform and opening up policy carried out by the Chinese government in 1982, all economic policies are guided by the market economy. In order to keep pace with the economic development trends of other countries in the world, Mainland China entering the WTO in 2001, which also help accelerated monetary system reform. The insurance industry is a key to China's economic construction, with premium income there increasing nearly 24 times between 1990 and 2006, making it one of the most attractive insurance markets in the world. After the full opening up of Taiwan's

James C. Hao, Ph.D., associate professor, Department of Insurance, Tamkang University; research fields: life insurance, annuity, pension, economic efficiency. 
insurance market in 1994, some well-known global insurers flooded into the country successively, with even more after entered the WTO in 2002. Taiwan's Finance Holding Company Law also help to loosen the restriction of inter-business operations for financial institutions greatly, so that financial firms could hold different properties such as banks, securities, insurance, etc. Because an insurance firm could enter various financial fields through the mode of a holding company, competition in Taiwan's insurance industry has risen.

Based on a comparison between the development state of Taiwan's insurance industry and that of Mainland China's, premium income in Taiwan in 1990 was 2.42 times that of Mainland China, ranking Taiwan six places higher than Mainland China globally. However, the premium income of Mainland China exceeded that of Taiwan for the first time in 2001, ranking higher than Taiwan globally for the first time. In 2005 and 2006 Taiwan ranked 13th, while Mainland China moved forward from the 11th in 2005 to the 9th in 2006. This obviously shows the growth outbreak of Mainland China's market and the gradual maturity and stability of Taiwan's market.

Although Mainland China's life insurance market has grown rapidly in recent years, as for the insurance density $^{1}$, there is a big gap across the Taiwan's straits. The average expenditure for life insurance by people in Mainland China in 2006 was US\$ 31.4, while that for people in Taiwan was US\$ 1800, or 57.32 times greater. As for the insurance penetration ${ }^{2}$, Taiwanese life insurance firms are at 11.6\%, 6.8 times that of Chinese Mainland's life insurance firms at $1.7 \%$. Taiwan is limited to its population and land area, yet its insurance development is far ahead of Mainland China, however, it is an unarguable fact that its development space and speed will fall behind Mainland China in the future. Although the insurance industry in Mainland China is not as developed as that in Taiwan presently, it is in a full development stage, and thus its future development deserves our attention.

This study intends to discuss whether there is any difference between the business performance of life insurance industries in Taiwan and Mainland China under different business environment backgrounds when domestic life insurance markets are facing heavy pressure from competition and with the impact of a low interest rate environment. There is a difference between the production technology levels and integrated operation environments of the life insurance industries in Taiwan and Mainland China. Without discussing them individually in the model, and by using the same production or cost functions, it may be difficult to obtain a correct measurement result. Therefore, this paper uses the Metafrontier oriented by input for analysis, because it is like the envelope curve in production theory thereby the individual group frontier of each country is found out, along with an envelope curve which contains the production functions of each country-namely the Metafrontier herein, and then the technical efficiency of each country can be compared. In addition, when evaluating the business performance, the operating management echelon will always be confronted with uncontrollable external environment variables. Therefore, this study applies the Four-Stage Data Envelopment Analysis to discuss the impact of business environment variables on business performance and re-evaluates the business efficiency of life insurance industries in Taiwan and Mainland China after adjusting the input variables.

\section{Research methods}

\subsection{Metafrontier model}

The DEA method is used for analyzing the efficiency of different DMUs. All similar DMUs are put together to figure out the efficiency values of various DMU. However, such an analysis mode may easily neglect the

\footnotetext{
${ }^{1}$ The insurance density refers to the ratio of gross premium income to national population, i.e. premium expenditure per capita.

2 The insurance penetration is namely the depth of insurance, which refers to the ratio of gross national premium income to GDP.
} 
source property of an individual DMU, meaning the differences among various DMU derived from different environmental backgrounds, e.g. environment variables such as economic civilization, laws and regulations, and political backgrounds. Applying the Metafrontier model can overcome the barriers resulting from the environment variables and analyze and measure the differences among various DMU which have different source properties. It can also be used for measuring the difference between each group of DMU and all DMUs.

Based on D.S. Praeada Rao (2006), this study evaluates the business performance of life insurance industries in Taiwan and Mainland China. If $y$ and $x$ are nonnegative output vector (Mx1) and input vector (Nx1), respectively, then for the firms many input-output combinations will come into being when facing diversified acquirable technologies. Therefore, the entire Metatechnology aggregation can be indicated as follow:

$$
T=\{(x, y): x \geq 0, y \geq 0 ; x \text { can produce } y\}
$$

When the input orientation uses the aggregation of input vector $x$ and all output vectors $y$, it is indicated as follow:

$$
L(y)=\{x:(x, y) \in T\}
$$

Referring to the frontier derived from these input aggregations, it is called Metafrontier. When evaluating the efficiency, the input metadistance function is used for describing the technology and is defined as follows:

$$
D(x, y)=\sup _{\lambda}\{\lambda>0:(x / \lambda) \in L(y)\}
$$

Here, $\lambda$ is the ratio of the input amount $(x)$ of the firm being evaluated to the output amount $\left(x^{*}\right)$ of its corresponding frontier. Hence, if $D(x, y)>1$, then this means the $x$ is inside the input aggregation $L(y)$. If $D(x, y)$ $=1$, then it means the $x$ is at the frontier of input aggregation $L(y)$.

If the existing technology aggregation represents the production efficiency of different groups of firms, then all firms are divided into $K$ groups $(K>1)$, assuming that within the limit of resources, regulations and environments, some groups of firms will not be able to use some technologies in Metatechnology aggregation. Therefore, for the firms in group $k$, the input-output combination can be obtained under the special technology aggregation of this group which can be indicated as follow:

$$
T^{k}=\{(x, y): x \geq 0 ; y \geq 0 ; x \text { is group } k \text { used for producing } y\}
$$

The group technology can also be indicated by group input aggregation and group input distance function, and it is defined as follows:

$$
\begin{gathered}
L^{k}(y)=\left\{x:(x, y) \in T^{k}\right\}, k=1,2, \ldots, \mathrm{K} \\
D^{k}(x, y)=\sup _{\lambda}\left\{\lambda .>0:(x / \lambda) \in L^{k}(y)\right\}, k=1,2, \ldots, \mathrm{K}
\end{gathered}
$$

The frontier formed by the input aggregation of these group firms is called group frontiers, and it has following properties:

(1) For any $k$, if $(x, y) \in T^{k}$, then $(x, y) \in T$;

(2) If $(x, y) \in T$, for some $k$, then $(x, y) \in T^{K}$;

(3) $T=\left\{T^{1} \cup T^{2} \cup \cdots \cup T^{K}\right\}$;

(4) For any $k, D^{k}(x, y) \leq D(x, y)$;

(5) $P(x)$ has convexity and does not always represents that $P^{k}(x), k=1,2, \ldots, \mathrm{K}$ has convexity, too.

As for Metatechnology, the input orientation technical efficiency of viewpoint $(\mathrm{x}, \mathrm{y})$ can be indicated as follow: 


$$
T E(x, y)=\frac{1}{D(x, y)}
$$

As for the frontier of Group $k$, the input orientation efficiency of viewpoint $(\mathrm{x}, \mathrm{y})$ can be indicated as equation (8). The higher (lower) $T E^{K}$ is, the closer (further) the actual input level of firms in group $k$ is to (from) the minimum input of Group $k$.

$$
\operatorname{TE}^{K}(x, y)=\frac{1}{D^{K}(x, y)}
$$

Due to $D^{k}(x, y) \leq D(x, y)$, the frontier of group $k$ is included in Metafrontier, and so there is a technology gap between them. The input orientation technology gap ratio (TGR) of each firm in group $k$ is defined as follow:

$$
\operatorname{TGR}^{k}(x, y)=\frac{D^{k}(x, y)}{D(x, y)}=\frac{T E(x, y)}{T E^{k}(x, y)}
$$

In equation (9), $T G R^{K}$ is between 0 and 1 , and if it is close to 1 , then it means the production frontier of group $k$ is close to the metafrontier, in other words, the production technology level is more advanced. Contrarily, the closer it is to 0 , the further the group frontier of group $k$ is from the Metafrontier, indicating a less developed production technology level.

\subsection{Four-stage data envelopment analysis}

Most past studies used one-stage Data Envelopment Analysis for discussing business performance, which puts all outputs, inputs and relevant environment variables into the model for an evaluation of producers' business performance. The advantage is that the production function does not need to be assumed, and various inputs and outputs are acceptable. The defect is that the selection of data is very sensitive, and if the same decision unit selects different input-output project, then different efficiency values can be obtained. If the data error is too large the analytic result is bound to be affected. Therefore, considering the one-stage DEA has some defects. Fried, et al (1999) proposed the Four-Stage Data Envelopment Analysis to adjust the active procedure of input-output for evaluating and adjusting the efficiency values of each stage, so as to promote business efficiency.

The first stage of Four-Stage DEA uses the original input-output data to figure out the efficiency value through the DEA model. The second stage takes the total input slack as the explained variable, takes the business environment variables as the explanatory variables, and uses Tobit regression equation for figuring out the estimated values of parameters:

$$
I S_{i j}^{t}=f_{j}\left(Z_{i j}^{t} \cdot \beta_{j}^{t} \cdot \varepsilon_{j}^{t}\right)
$$

Here, $I S_{i j}^{t}$ is the input slack value of a certain element when No.i DMU puts $j$ units in Phase $t ; Z_{i j}^{t}$ is the variable vector which means the impact on the business environment when No.i firm uses $j$ input; $\beta_{j}^{t}$ is the corresponding coefficient vector, and $\varepsilon_{j}^{t}$ is the random disturbance term.

The third stage takes the estimated value into the regression equation, and the estimated aggregation of the anticipated slack is calculculated to adjust the original input data, the model is as follow:

$$
I \hat{S}_{i j}^{t}=f_{j}\left(Z_{i j}^{t} \cdot \hat{\beta}_{j}\right)
$$

In addition, referring to the input variables adjusting method put forward by Fried, Lovell, Schmidt and Yaisawarng (1999), each input variable data is adjusted, for the purpose of making each DUM face the same business environment:

$$
X_{i j}^{t^{\text {adjusted }}}=X_{i j}^{x}+\left[\operatorname{Max}\left\{I \hat{S}_{i j}^{t}\right\}-I \hat{S}_{i j}^{t}\right]
$$


where, $X_{i j}^{t^{\text {adjuested }}}$ is a certain input variable data of No.i DMU after adjustment in Phase $t ; X_{i j}^{t}$ is the original input variable data of No.i DMU, and $\operatorname{Max}\left\{\hat{S}_{i j}^{t}\right\}$ is the anticipated maximum value of input slack variables of input $j$ of No. $i$ firm in Phase $t$.

In the fourth stage the efficiency value of each producer is re-calculated through DEA based on the adjusted input data and original output data after the environment variables are taken into consideration. Therefore, the efficiency value obtained in this stage is the efficiency value after the environment variables are removed, and only the efficiency value affected by the management aspect remains thus, the efficiency value of each production can be measured more objectively.

\subsection{Dynamic DEA}

The efficiency value measured out by general Data Envelopment Analysis is of each producer in one single year. Conversely, the dynamic DEA is able to calculate the efficiency value of a period of time through a concept of commutation, and it compares the estimated results of these two methods. Assuming there are $J$ firms, $X_{t}$ is the input amount of $m \times 1$ used in Phase $t$, while $y_{t}$ is the output vector of $n \times 1$ in Phase $t$, whereby the firms use $x_{t}$ for producing $y_{t}$. This paper applies the dynamic DEA model structure to estimating the technology efficiency of firms when using $X_{t}$ for producing $y_{t}$. Based on DEA, in fixed returns to scale, the frontier of cost efficiency of 1 to $T$ years can be defined as follow:

$$
T E_{j}=\min _{\left\{\phi_{t}, z_{t}\right\}}\left\{\sum_{t=1}^{T} \gamma^{t-1} \phi_{t} w_{t}^{\prime} \bar{x}_{t} / \bar{C} \mid X_{t} z_{t} \leq \phi_{t} \bar{x}_{t}, Y_{t} z_{t} \geq \bar{y}_{t}, t=1,2, \ldots, T\right\}
$$

In equation (13), $\gamma$ is a fixed discount factor, $w_{t}$ is the input price vector of $m \times 1$ in phase $t, T$ is a fixed value, and $z_{t}$ is the intensity vector of $J \times 1$. Here, $\bar{x}_{t}$ and $\bar{y}_{t}$ are the practical observed values of input and output variables in year $t, \bar{C}$ is the discounted sum of actual costs to phase $T$, and $\phi_{t}=D_{t}^{-1}$ is the technical efficiency value in year $t$ without regard to the input price factor.

While under variable returns to scale, the technical efficiency of No. $j$ firm from year 1 to $T$ can be calculated through following equation:

$$
T E v_{j}=\min _{\left\{\phi, z_{t}\right\}}\left\{\sum_{t=1}^{T} \gamma^{t-1} \phi_{t} w_{t}^{\prime} \bar{x}_{t} / \bar{C} \mid X_{t} z_{t} \leq \phi_{t} \bar{x}_{t}, Y_{t} z_{t} \geq \bar{y}_{t}, \sum z_{t}=1, t=1,2, \ldots, T\right\}
$$

\section{Data collection and research subjects}

The empirical period of this study is from 2003 to 2005. The main data sources incude Life insurance business annual report and Insurance yearbook published by Taiwan Insurance Institute; open information of life insurance companies in Taiwan promulgated on their websites, China insurance yearbook, and the statistical data from China Insurance Regulatory Commission is adopted as secondary data. The data from both sides are integrated and sorted out herein.

Because the information of life insurance companies in Taiwan and Mainland China is not complete, and the establishment time didn't conform to the actual one in the course of research, in order to increase the isomorphism type of research samples to avoid the impact of extreme samples on the research result, a part of the research samples is excluded. Therefore, the main research object of this study contains 43 life insurance companies, including 19 companies in Taiwan: Central Insurance, Taiwan Life Insurance, Prudential, Cathay, China 
Discussion on the business performance of life insurance industries in Taiwan and Mainland China - Application of Metafrontier model

Insurance, Nanshan, Shinkong, Prudential Finance, Fubon, Global Life, MassMutual, Singfor, Sinon, Far Glory, Hon Tai, Allianz, Aegon, MetLife and ING; and 24 in Mainland China: China Life Insurance, Pacific Life Insurance, Ping An Life Insurance, New China Life Insurance, Taikang Life Insurance, Taiping Life Insurance, Minsheng Life Insurance, Sino Life Insurance, Manulife-Sinochem Life Insurance, Pacific-Antai Life Insurance, Allianz China Life Insurance, AXA Minmetals Life Insurance, CITIC-Prudential Life Insurance, China CMG Life Insurance, John Hancock Tianan Life Insurance, Generali China Life Insurance, Sun Life Everbright Life Insurance, AIA Life Insurance, Haier New York Life Insurance, ING Capital Life Insurance, Aviva-COFCO Life Insurance, AEGON-CNOOC Life Insurance, CIGNA \& CMC Life Insurance, and Nissay-SVA Life Insurance.

Table 1 Total input slack variable of each life insurance company in each year in Mainland China

\begin{tabular}{|c|c|c|c|c|c|c|c|c|c|}
\hline \multirow{2}{*}{ Name of company } & \multicolumn{3}{|c|}{2003} & \multicolumn{3}{|c|}{2004} & \multicolumn{3}{|c|}{2005} \\
\hline & Slack1 & Slack2 & Slack3 & Slack1 & Slack2 & Slack3 & Slack1 & Slack2 & Slack3 \\
\hline China Life Insurance & 0.000 & 0.000 & 0.000 & 0.000 & 0.000 & 0.000 & 0.000 & 0.000 & 0.000 \\
\hline Pacific Life Insurance & 0.000 & 0.000 & 0.000 & 0.000 & 0.000 & 0.000 & 1027.081 & 514.266 & 13475.820 \\
\hline Ping An Life Insurance & 0.000 & 0.000 & 0.000 & 0.000 & 0.000 & 0.000 & 10801.620 & 547.761 & 32572.070 \\
\hline New China Life Insurance & 0.000 & 0.000 & 0.000 & 0.000 & 0.000 & 0.000 & 0.000 & 0.000 & 0.000 \\
\hline Taikang Life Insurance & 0.000 & 0.000 & 0.000 & 2428.784 & 118.278 & 15601.500 & 0.000 & 0.000 & 0.000 \\
\hline Taiping Life Insurance & 0.000 & 0.000 & 0.000 & 610.086 & 120.504 & 3502.378 & 0.000 & 0.000 & 0.000 \\
\hline Minsheng Life Insurance & 176.315 & 84.961 & 3100.842 & 0.000 & 0.000 & 0.000 & 0.000 & 0.000 & 0.000 \\
\hline Sino Life Insurance & 144.264 & 33.794 & 8591.214 & 0.000 & 0.000 & 0.000 & 0.000 & 0.000 & 0.000 \\
\hline $\begin{array}{l}\text { Manulife-Sinochem Life } \\
\text { Insurance }\end{array}$ & 0.000 & 0.000 & 0.000 & 0.000 & 0.000 & 0.000 & 0.000 & 0.000 & 0.000 \\
\hline $\begin{array}{ll}\text { Pacific-Antai } & \text { Life } \\
\text { Insurance } & \\
\end{array}$ & 117.368 & 94.729 & 739.684 & 117.550 & 123.326 & 1157.597 & 6313.085 & 1718.426 & 32400.800 \\
\hline $\begin{array}{lll}\text { Allianz } & \text { China } & \text { Life } \\
\text { Insurance } & & \\
\end{array}$ & 52.275 & 62.711 & 393.832 & 15.360 & 59.321 & 151.900 & 0.000 & 0.000 & 0.000 \\
\hline $\begin{array}{ll}\text { AXA Minmetals Life } \\
\text { Insurance }\end{array}$ & 79.388 & 22.635 & 509.211 & 121.450 & 7.845 & 147.808 & 88.915 & 7.617 & 2573.981 \\
\hline $\begin{array}{ll}\text { Nissay-SVA } & \text { Life } \\
\text { Insurance } & \\
\end{array}$ & 0.000 & 0.000 & 0.000 & 2.000 & 16.385 & 31.154 & 0.000 & 0.000 & 0.000 \\
\hline $\begin{array}{ll}\text { CITIC-Prudential Life } \\
\text { Insurance }\end{array}$ & 221.369 & 14.049 & 389.050 & 0.000 & 0.000 & 0.000 & 0.000 & 0.000 & 0.000 \\
\hline $\begin{array}{lll}\text { China } & \text { CMG } & \text { Life } \\
\text { Insurance } & & \\
\end{array}$ & 0.000 & 0.000 & 0.000 & 0.000 & 0.000 & 0.000 & 343.284 & 64.277 & 8508.183 \\
\hline $\begin{array}{l}\text { John Hancock Tianan Life } \\
\text { Insurance }\end{array}$ & 10.103 & 22.300 & 59.058 & 0.000 & 0.000 & 0.000 & 0.000 & 0.000 & 0.000 \\
\hline $\begin{array}{lll}\text { Generali } & \text { China } & \text { Life } \\
\text { Insurance } & & \\
\end{array}$ & 76.903 & 26.677 & 786.120 & 0.000 & 0.000 & 0.000 & 293.481 & 1293.395 & 9568.577 \\
\hline $\begin{array}{l}\text { Sun Life Everbright Life } \\
\text { Insurance }\end{array}$ & 82.006 & 94.887 & 536.722 & 42.694 & 99.634 & 320.162 & 0.000 & 0.000 & 0.000 \\
\hline AIA Life Insurance & 0.000 & 0.000 & 0.000 & 0.000 & 0.000 & 0.000 & 0.000 & 0.000 & 0.000 \\
\hline $\begin{array}{l}\text { Haier New York Life } \\
\text { Insurance }\end{array}$ & 0.000 & 0.000 & 0.000 & 67.472 & 38.286 & 71.227 & 0.000 & 0.000 & 0.000 \\
\hline $\begin{array}{ll}\text { ING Capital Life } \\
\text { Insurance }\end{array}$ & 107.486 & 42.702 & 654.698 & 102.105 & 49.828 & 793.084 & 117.463 & 43.355 & 679.776 \\
\hline Aviva-COFCO & 54.217 & 45.945 & 1086.592 & 149.657 & 65.686 & 945.337 & 0.000 & 0.000 & 0.000 \\
\hline AEGON-CNOOC & 52.362 & 33.206 & 110.118 & 0.000 & 0.000 & 0.000 & 314.721 & 134.822 & 574.114 \\
\hline CIGNA \&CMC & 0.000 & 0.000 & 0.000 & 81.652 & 1.250 & 63.850 & 0.000 & 0.000 & 0.000 \\
\hline
\end{tabular}

This paper selects the variables with reference to the relevant literature to the business performance of internal and external insurance industries, by considering the operation properties of life insurance industries in 
Taiwan and Mainland China, and selecting the same input variables, input price variables and output variables. Any amount variable will become a real variable after deflation of CPI with a base period of 2001, Table 1 defines each variable.

Because the managerial abilities of business managers usually undergo a reciprocal effect of controllable and uncontrollable factors, this result is present on the business performance of the company. The uncontrollable factor thereof is usually called an external variable, which is always related to the operating environment, including the overall environment such as government policies and regulations, market structure, regional properties and the decision unit properties such as ownership (e.g. publicly-operated or privately-operated) and scale. As some life insurance companies have favorable operating conditions while some have unfavorable ones, all life insurance companies can face the same operating environment after the adjustment of environment variables. Therefore, this study considers the impact of business environment factors (environment variables) in which the operating management echelon cannot control business efficiency. Thus, life insurance industries in Taiwan and Mainland China select the same environment variables (Model II) for analysis. All the environment variables of following Model II are set as dummy variables for analysis.

(1) Establishment time: 1 is set for an establishment time over 30 years, 0 for less than 30 years.

(2) Company type: 1 is a domestic life insurance company, 0 is a foreign life insurance company.

(3) Region code: Life insurance companies in Taiwan are set as 1, those in Mainland China are 0.

(4) Paid-up capital: The paid-up capital exceeding US\$3 billion is set as 1, and that below US\$3 billion is set as 0 .

(5) Listed and over-the-counter: Life insurance companies are divided into two types the listed and over-the-counter ones are set as 1 , and those unlisted and non-over-the-counter ones are set as 0 .

(6) Market share: The market share refers to the ratio of each company's life insurance premium income to total life insurance premium income. 1 is set for a life insurance company whose market share is more than $3 \%$, and 0 for the company whose market share is less than $3 \%$.

\section{Empirical analysis}

This study adopts the DEA method, assuming variable returns to scale to evaluate and comparatively analyze the business performance of life insurance industries in Taiwan and Mainland China based on "BBC input orientation". Aside from calculating the efficiency of each life insurance company in an inter-period accumulative year, it also calculates the joint efficiency of life insurance industries in Taiwan and Mainland China when using Metafrontier. It further measures the TGR of each life insurance company, and it applies the Four-Stage DEA to evaluate the impact of environment variables on the business performance so as to measure the business performance of the life insurance industry more objectively. The demonstration period adopted by this study is from 2003 to 2005, and the research subject is 43 life insurance companies: 19 in Taiwan and 24 in Mainland China. There are 129 sets of sample data, and it is assumed that the discount rate is $\gamma(\gamma$ is set as $3 \%$ in this paper) to figured out the change of each life insurance company in technical efficiency in the inter-period accumulative years from 2003 to 2005 .

\subsection{Step 1: DEA efficiency analysis}

4.1.1 Estimated technical efficiency value $\left(\mathrm{K}_{\mathrm{i}}-\mathrm{PTE} 1^{*}\right)$ based on each group frontier

As for the efficiency value estimated by each group frontier (see Table 4), Taiwan's average efficiency value 
is 0.917 , while Mainland China's is 0.929 . It is found that the efficiency value of Taiwan's life insurance industry declines with the increase of the accumulative period, while Mainland China's life insurance industry is contrary to Taiwan's. According to the groups, 11 companies in Taiwan such as Central Life Insurance, Taiwan Life Insurance, Cathay, and China Life have technical efficiency, but the other 6 life insurance companies have no technical efficiency, whereas Prudential (0.600), MassMutual (0.662) and Hon Tai (0.688) have bad relative efficiency. Seven companies in Mainland China have technical efficiency, and the other 17 life insurance companies have no technical efficiency, among which, some companies have bad relative efficiency such as ING Capital Life Insurance (0.629), Aviva-COFCO Life Insurance (0.777) and AEGON-CNOOC Life Insurance (0.780), but the average efficiency of these three companies show an obvious increase with the increase of accumulative period.

\subsubsection{Estimated technical efficiency value $\left(\mathrm{M}_{\mathrm{i}}-\mathrm{PTE} 1^{*}\right)$ based on metafrontier}

The average technical efficiency value of life insurance industries in Taiwan and Mainland China is 0.814 , which means the present input amount of all life insurance companies only reaches $81.4 \%$ of the level under metafrontier. Thus, the average technical efficiency of Taiwan is 0.891 , which is higher than Mainland China's 0.754. On average, at the same technical level, the technical efficiency of Taiwan's life insurance industry is better than that of Mainland China's. Among the firms, 14 have technical efficiency under Metafrontier, while 29 have no technical efficiency, including 11 companies in Taiwan, and only 3 in Mainland China which are China Life Insurance, New China Life Insurance and China CMG Life Insurance. This means there is an obvious gap in the average technology of operations between the life insurance industries in Taiwan and Mainland China. According to the inspection data, along with the great growth of technical efficiency in Mainland China's life insurance companies, some companies such as Ping An Life Insurance, Taikang Life Insurance, Taiping Life Insurance, Manulife-Sinochem Life Insurance, and AIA Life Insurance are showing a decline, which reveals a waste of resources of these three companies from the operating management over the three years.

\subsubsection{Technology gap ratio}

The TGR of Taiwan's life insurance industry is 0.968 , or on an average, the technical efficiency of Taiwan's life insurance industry has reached $96.8 \%$ of the technical level of the whole life insurance industry. The average of Mainland China's life insurance industry is 0.808 , or the technical efficiency of Mainland China's life insurance industry has reached $89.4 \%$ of the technical level of the whole life insurance industry. Hence, the technical level of Taiwan's life insurance industry is more advanced than that of Mainland China's. Eighteen companies' TGR is 1, including 11 companies in Taiwan and 7 companies in Mainland China. According to the inspection data, the TGR of 3 companies in Mainland China including Taiping Life Insurance (0.503), Minsheng Life Insurance (0.425) and CITIC-Prudential Life Insurance (0.576) is the lowest among all the firms.

\subsection{Step 2: Tobit regression analysis}

Considering the impact of business environment factors (environment variables) of which the operating management echelon cannot control on business efficiency, this paper considers that both life insurance industries select the same environment variables (Model II) for analysis. Model II thereof take up six environment variables. Tobit regression analysis is applied, the total input slack variables are used as dependent variables, and the environment variables are used as independent variables for the basis of adjusting the input variables. The following two parts provide an explanation:

\subsubsection{Total input slack variables analysis}

This study adopts three kinds of element inputs, so that each life insurance company has 3 total input slacks 
Discussion on the business performance of life insurance industries in Taiwan and Mainland China -Application of Metafrontier model

which shall be figured out. The required total input slacks in this study on staff number (X1), fixed assets (X2) and investment expenditure (X3) are indicated as Slack1, Slack2 and Slack3, respectively.

Table 1 and Table 2 show the target value of input and improvable space of non-effective life insurance companies in Taiwan and Mainland China for each year.

Table 2 Total input slack variable of each life insurance company in Taiwan

\begin{tabular}{|c|c|c|c|c|c|c|c|c|c|}
\hline & \multicolumn{3}{|c|}{2003} & \multicolumn{3}{|c|}{2004} & \multicolumn{3}{|c|}{2005} \\
\hline $\begin{array}{l}\text { Name } \\
\text { of company }\end{array}$ & Slack1 & Slack2 & Slack3 & Slack1 & Slack2 & Slack3 & Slack1 & Slack2 & Slack3 \\
\hline $\begin{array}{ll}\text { Bank } \\
\text { Taiwan }\end{array}$ & 0.000 & 0.000 & 0.000 & 0.000 & 0.000 & 0.000 & 0.000 & 0.000 & 0.000 \\
\hline Taiwan Life & 672.601 & 223.291 & 8494.697 & 1270.703 & 416.978 & 21652.320 & 1027.081 & 514.266 & 13475.820 \\
\hline Prudential & 10149.420 & 781.381 & 14578.150 & 10076.100 & 651.721 & 20109.450 & 10801.620 & 547.761 & 32572.070 \\
\hline Cathay & 0.000 & 0.000 & 0.000 & 0.000 & 0.000 & 0.000 & 0.000 & 0.000 & 0.000 \\
\hline China Life & 0.000 & 0.000 & 0.000 & 0.000 & 0.000 & 0.000 & 0.000 & 0.000 & 0.000 \\
\hline Nanshan & 0.000 & 0.000 & 0.000 & 0.000 & 0.000 & 0.000 & 0.000 & 0.000 & 0.000 \\
\hline Shinkong & 0.000 & 0.000 & 0.000 & 0.000 & 0.000 & 0.000 & 0.000 & 0.000 & 0.000 \\
\hline Fubon & 0.000 & 0.000 & 0.000 & 0.000 & 0.000 & 0.000 & 0.000 & 0.000 & 0.000 \\
\hline Global Life & 0.000 & 0.000 & 0.000 & 0.000 & 0.000 & 0.000 & 0.000 & 0.000 & 0.000 \\
\hline Mass Mutual & 7424.469 & 1394.147 & 16578.980 & 5704.093 & 1231.031 & 21120.960 & 6313.085 & 1718.426 & 32400.800 \\
\hline Sinon & 0.000 & 0.000 & 0.000 & 0.000 & 0.000 & 0.000 & 0.000 & 0.000 & 0.000 \\
\hline Singfor & 100.819 & 7.569 & 1558.670 & 116.269 & 11.748 & 3182.189 & 88.915 & 7.617 & 2573.981 \\
\hline Far Glory & 23.734 & 278.137 & 289.718 & 0.000 & 1.562 & 0.000 & 0.000 & 0.000 & 0.000 \\
\hline Hon Tai & 879.347 & 125.136 & 8055.826 & 496.457 & 103.327 & 8762.658 & 343.284 & 64.277 & 8508.183 \\
\hline Allianz & 0.000 & 0.000 & 0.000 & 0.000 & 0.000 & 0.000 & 0.000 & 0.000 & 0.000 \\
\hline $\begin{array}{l}\text { Prudential } \\
\text { Finance }\end{array}$ & 0.000 & 0.000 & 0.000 & 0.000 & 0.000 & 0.000 & 293.481 & 1293.395 & 9568.577 \\
\hline Aegon & 0.000 & 0.000 & 0.000 & 0.000 & 0.000 & 0.000 & 0.000 & 0.000 & 0.000 \\
\hline MetLife & 0.000 & 0.000 & 0.000 & 0.000 & 0.000 & 0.000 & 0.000 & 0.000 & 0.000 \\
\hline ING & 1222.350 & 0.931 & 60080.350 & 599.845 & 4.110 & 93866.670 & 0.000 & 0.000 & 0.000 \\
\hline
\end{tabular}

4.2.2 Evaluate the impact of environment variables on business efficiency

According to Table 3, the region, listing and over-the-counter have an obvious relation with the staff number slack variables in 2003, and redundant personnel is more likely to occur in Taiwan than in Mainland China, while the listed and over-the-counter companies have no redundant personnel. Listing and over-the-counter have a negative and notable relation with the fixed assets slack variables and investment expenditure slack variables. In 2004, the company type, paid-up capital and region exert an obvious impact on the staff number slack variable and investment expenditure slack variable, respectively. The former one represents that the domestic life insurance companies have no redundant personnel, but much more paid-up capital are inputted. The latter one represents that Taiwan's life insurance companies input less investment expenditure than Mainland China's insurance companies do. In 2005, Taiwan had no excessive input on the application of fixed assets and investment expenditure compared with Mainland China. 
Discussion on the business performance of life insurance industries in Taiwan and Mainland China - Application of Metafrontier model

Table 3 Estimation of environment variables on business efficiency

\begin{tabular}{|c|c|c|c|c|c|c|}
\hline \multicolumn{7}{|c|}{2003} \\
\hline $\begin{array}{r}\text { Dependent } \\
\text { variable }\end{array}$ & \multicolumn{2}{|c|}{ Staff number slack variable } & \multicolumn{2}{|c|}{ Fixed assets slack variable } & \multicolumn{2}{|c|}{$\begin{array}{c}\text { Investment expenditure } \\
\text { slack variable }\end{array}$} \\
\hline $\begin{array}{l}\text { Independent } \\
\text { variable }\end{array}$ & Estimated coefficient & T value & Estimated coefficient & T value & Estimated coefficient & T value \\
\hline Establishment date & -145.0958 & -0.14 & -127.992 & -0.88 & 17160.83 & 1.21 \\
\hline Company type & -1375.363 & -1.38 & -46.10645 & -0.32 & 5395.65 & 0.39 \\
\hline Region & $1518.312^{*}$ & 1.78 & 105.9257 & 0.86 & 8389.679 & 0.71 \\
\hline Paid-up capital & 1478.742 & 1.52 & 182.9483 & 1.29 & 297.8006 & 0.02 \\
\hline Listed, over-the-counter & $-3789.734 * *$ & -2.59 & $-449.956^{* *}$ & -2.17 & $-67791.69 * * *$ & -3.32 \\
\hline Market share & 1168.501 & 1.26 & 65.29198 & 0.49 & $27751.05 * *$ & 2.12 \\
\hline \multicolumn{7}{|c|}{2004} \\
\hline $\begin{array}{r}\text { Dependent } \\
\text { variable }\end{array}$ & \multicolumn{2}{|c|}{ Staff number slack variable } & \multicolumn{2}{|c|}{ Fixed assets slack variable } & \multicolumn{2}{|c|}{$\begin{array}{c}\text { Investment expenditure } \\
\text { slack variable }\end{array}$} \\
\hline $\begin{array}{l}\text { Independent } \\
\text { variable }\end{array}$ & Estimated coefficient & T value & Estimated coefficient & T value & Estimated coefficient & T value \\
\hline Establishment date & -1436.799 & -1.12 & 166.7225 & 0.43 & 1100.894 & 0.04 \\
\hline Company type & $-2394.19 *$ & -1.74 & -29.26102 & -0.07 & -27066.21 & -0.89 \\
\hline Region & 430.3385 & 0.48 & -163.4743 & -0.60 & $-33872.94 *$ & -1.73 \\
\hline Paid-up capital & $3588.525 * *$ & 2.54 & 168.2758 & 0.40 & 30672.15 & 0.97 \\
\hline Listed, over-the-counter & -756.7964 & -0.51 & -405.061 & -0.89 & 20830.08 & 0.66 \\
\hline Market share & -836.9216 & -0.79 & -197.8016 & -0.61 & 12831.66 & 0.55 \\
\hline \multicolumn{7}{|c|}{2005} \\
\hline $\begin{array}{r}\text { Dependent } \\
\text { variable }\end{array}$ & \multicolumn{2}{|c|}{ Staff number slack variable } & \multicolumn{2}{|c|}{ Fixed assets slack variable } & \multicolumn{2}{|c|}{$\begin{array}{c}\text { Investment expenditure } \\
\text { slack variable }\end{array}$} \\
\hline $\begin{array}{l}\text { Independent } \\
\text { variable }\end{array}$ & Estimated coefficient & $\mathrm{T}$ value & Estimated coefficient & T value & Estimated coefficient & T value \\
\hline Establishment date & 1981.721 & 1.27 & 714.7357 & 1.62 & $102564.1 * *$ & 2.36 \\
\hline Company type & 932.8344 & 0.59 & 731.2203 & 1.60 & $81722.57 *$ & 1.82 \\
\hline Region & -1433.469 & -1.15 & $-837.7091 * *$ & -2.37 & $-108060.3^{* * *}$ & -3.13 \\
\hline Paid-up capital & 1250.678 & 0.78 & -76.08087 & -0.17 & -37039.37 & -0.83 \\
\hline Listed, over-the-counter & -3001.285 & -1.50 & -634.8651 & -1.14 & -42732.06 & -0.80 \\
\hline Market share & -525.7849 & -0.36 & -86.42328 & -0.21 & 11736.71 & 0.29 \\
\hline
\end{tabular}

\subsection{Step 3: Adjustment of input variables}

The impact effect resulting from the above Tobit regression analysis is adjusted in Model II, whereby it is found that the "region" and "listed and over-the-counter companies" influence the input slack variable the most. Therefore, Step 3 makes adjustment base on three original input variables and uses equation (11) and equation (12) to adjust the input amount of three elements, the adjustment aims at life insurance companies in a favorable operating environment, and their element input is increased by a large degree while life insurance companies in an unfavorable operating environment have less adjustment, or even no adjustment.

\subsection{Step 4: Re-measurement of efficiency value}

4.4.1 Estimated technical efficiency value based on each group frontier $\left(K_{i}-P T E 2^{*}\right)$

In Table 4, the average technical efficiency value of Taiwan is 0.936 , while that of Mainland China is 0.967 . Eleven life insurance companies in Taiwan have technical efficiency, and 8 companies have no technical efficiency, of which 8 companies have an inferior efficiency value, including Taiwan Life (0.778) and Prudential (0.775). Seven companies in Mainland China have technical efficiency, including China Life Insurance, Pacific Life Insurance, Ping An Life Insurance, New China Life Insurance, Manulife-Sinochem Life Insurance, China 
Discussion on the business performance of life insurance industries in Taiwan and Mainland China -Application of Metafrontier model

CMG Life Insurance, and AIA Life Insurance.

4.4.2 Estimated technical efficiency value based on Metafrontier $\left(M_{i}-P T E 2^{*}\right)$

Table 4 Comparison of various efficiency values of original data in Model II inter-period accumulative years (2003-2005)

\begin{tabular}{|c|c|c|c|c|c|c|c|c|c|c|}
\hline & \multicolumn{3}{|c|}{$\begin{array}{l}\text { Metafrontier technical } \\
\text { efficiency value }\end{array}$} & \multicolumn{3}{|c|}{$\begin{array}{c}\text { Group frontiers technical } \\
\text { efficiency value }\end{array}$} & \multicolumn{3}{|c|}{ TGR } \\
\hline & & $\mathrm{M}_{i}-P T E 1^{*}$ & $\mathrm{M}_{i}-P T E 2^{*}$ & $\begin{array}{c}\text { Increase } \\
\text { (decrease)\% }\end{array}$ & $K_{i}-P T E 1^{*}$ & $K_{i}-P T E 2^{*}$ & $\begin{array}{c}\text { Increase } \\
\text { (decrease) } \%\end{array}$ & $T G R 1_{i}^{*}$ & $T G R 2_{i}^{*}$ & \begin{tabular}{|c|} 
Increase \\
(decrease)\%
\end{tabular} \\
\hline \multirow{19}{*}{$\begin{array}{l}\text { Taiwan } \\
\text { region }\end{array}$} & $\begin{array}{|lr|}\begin{array}{l}\text { Bank of Taiwan } \\
\text { (formerly } \\
\text { Central Bank) }\end{array} \\
\end{array}$ & 1.000 & 1.000 & 0.00 & 1.000 & 1.000 & 0.00 & 1.000 & 1.000 & 0.00 \\
\hline & Taiwan Life & 0.829 & 0.748 & -9.77 & 0.829 & 0.778 & -6.15 & 1.000 & 0.962 & -3.80 \\
\hline & Prudential & 0.575 & 0.608 & 5.74 & 0.600 & 0.775 & 29.17 & 0.959 & 0.785 & -18.14 \\
\hline & Cathay & 1.000 & 1.000 & 0.00 & 1.000 & 1.000 & 0.00 & 1.000 & 1.000 & 0.00 \\
\hline & China Life & 1.000 & 0.893 & -10.70 & 1.000 & 0.914 & -8.60 & 1.000 & 0.977 & -2.30 \\
\hline & Nanshan & 0.994 & 0.996 & 0.20 & 1.000 & 1.000 & 0.00 & 0.994 & 0.996 & 0.20 \\
\hline & Shinkong & 1.000 & 0.994 & -0.60 & 1.000 & 1.000 & 0.00 & 1.000 & 0.994 & -0.60 \\
\hline & Fubon & 1.000 & 1.000 & 0.00 & 1.000 & 1.000 & 0.00 & 1.000 & 1.000 & 0.00 \\
\hline & Global Life & 1.000 & 0.849 & -15.10 & 1.000 & 0.995 & -0.50 & 1.000 & 0.854 & -14.60 \\
\hline & Mass Mutual & 0.642 & 0.688 & 7.17 & 0.662 & 0.808 & 22.05 & 0.970 & 0.851 & -12.27 \\
\hline & Sinon & 0.792 & 0.600 & -24.24 & 1.000 & 0.925 & -7.50 & 0.792 & 0.649 & -18.06 \\
\hline & Singfor & 0.908 & 0.734 & -19.16 & 0.912 & 0.953 & 4.50 & 0.995 & 0.771 & -22.51 \\
\hline & Far Glory & 0.994 & 0.863 & -13.18 & 0.997 & 1.000 & 0.30 & 0.997 & 0.863 & -13.44 \\
\hline & Hon Tai & 0.674 & 0.599 & -11.13 & 0.688 & 0.856 & 24.42 & 0.980 & 0.699 & -28.67 \\
\hline & Allianz & 1.000 & 1.000 & 0.00 & 1.000 & 1.000 & 0.00 & 1.000 & 1.000 & 0.00 \\
\hline & Prudential Finance & 0.520 & 0.631 & 21.35 & 0.728 & 0.803 & 10.30 & 0.714 & 0.786 & 10.08 \\
\hline & Aegon & 0.998 & 1.000 & 0.20 & 1.000 & 1.000 & 0.00 & 0.998 & 1.000 & 0.20 \\
\hline & MetLife & 1.000 & 0.863 & -13.70 & 1.000 & 0.977 & -2.30 & 1.000 & 0.883 & -11.70 \\
\hline & ING & 0.997 & 1.000 & 0.30 & 0.999 & 1.000 & 0.10 & 0.998 & 1.000 & 0.20 \\
\hline \multirow{12}{*}{$\begin{array}{c}\text { Mainland } \\
\text { China }\end{array}$} & $\begin{array}{|ll|}\begin{array}{l}\text { China } \\
\text { Insurance }\end{array} & \text { Life } \\
\end{array}$ & 1.000 & 1.000 & 0.00 & 1.000 & 1.000 & 0.00 & 1.000 & 1.000 & 0.00 \\
\hline & \begin{tabular}{|l|} 
China Pacific Life \\
Insurance
\end{tabular} & 0.910 & 0.937 & 2.97 & 1.000 & 1.000 & 0.00 & 0.910 & 0.937 & 2.97 \\
\hline & $\begin{array}{l}\text { China Ping An Life } \\
\text { Insurance }\end{array}$ & 0.939 & 0.943 & 0.43 & 1.000 & 1.000 & 0.00 & 0.939 & 0.943 & 0.43 \\
\hline & \begin{tabular}{|l|} 
New China Life \\
Insurance
\end{tabular} & 1.000 & 1.000 & 0.00 & 1.000 & 1.000 & 0.00 & 1.000 & 1.000 & 0.00 \\
\hline & $\begin{array}{|ll|}\text { Taikang } & \text { Life } \\
\text { Insurance } & \\
\end{array}$ & 0.742 & 0.835 & 12.53 & 0.941 & 0.944 & 0.32 & 0.789 & 0.885 & 12.17 \\
\hline & $\begin{array}{|ll|}\text { Taiping } & \text { Life } \\
\text { Insurance } & \\
\end{array}$ & 0.492 & 0.793 & 61.18 & 0.978 & 0.947 & -3.17 & 0.503 & 0.838 & 66.60 \\
\hline & \begin{tabular}{|l} 
Minsheng Life \\
Insurance
\end{tabular} & 0.400 & 0.929 & 132.25 & 0.941 & 0.982 & 4.36 & 0.425 & 0.946 & 122.59 \\
\hline & Sino Life Insurance & 0.813 & 0.982 & 20.79 & 0.986 & 0.995 & 0.91 & 0.824 & 0.987 & 19.78 \\
\hline & \begin{tabular}{|l|}
$\begin{array}{l}\text { Manulife-Sinochem } \\
\text { Life Insurance }\end{array}$ \\
\end{tabular} & 0.672 & 0.841 & 25.15 & 1.000 & 1.000 & 0.00 & 0.672 & 0.841 & 25.15 \\
\hline & \begin{tabular}{|l|} 
Pacific-Antai Life \\
Insurance
\end{tabular} & 0.604 & 0.803 & 32.95 & 0.864 & 0.886 & 2.55 & 0.700 & 0.907 & 29.57 \\
\hline & \begin{tabular}{|l|} 
Allianz China Life \\
Insurance
\end{tabular} & 0.679 & 0.856 & 26.07 & 0.863 & 0.947 & 9.73 & 0.787 & 0.904 & 14.87 \\
\hline & $\begin{array}{l}\text { AXA Minmetals } \\
\text { Life Insurance }\end{array}$ & 0.577 & 0.872 & 51.13 & 0.852 & 0.943 & 10.68 & 0.677 & 0.925 & 36.63 \\
\hline
\end{tabular}


Discussion on the business performance of life insurance industries in Taiwan and Mainland China -Application of Metafrontier model

\begin{tabular}{|c|c|c|c|c|c|c|c|c|c|}
\hline \begin{tabular}{|l|} 
CITIC-Prudential \\
Life Insurance
\end{tabular} & 0.558 & 0.825 & 47.85 & 0.969 & 0.883 & -8.88 & 0.576 & 0.934 & 62.15 \\
\hline \begin{tabular}{|l|l|}
$\begin{array}{l}\text { China CMG Life } \\
\text { Insurance }\end{array}$ \\
\end{tabular} & 1.000 & 1.000 & 0.00 & 1.000 & 1.000 & 0.00 & 1.000 & 1.000 & 0.00 \\
\hline $\begin{array}{|lr|}\text { John } & \text { Hancock } \\
\text { Tianan } & \text { Life } \\
\text { Insurance } & \\
\end{array}$ & 0.936 & 0.942 & 0.64 & 0.970 & 0.995 & 2.58 & 0.964 & 0.947 & -1.76 \\
\hline $\begin{array}{l}\text { Generali China Life } \\
\text { Insurance }\end{array}$ & 0.976 & 0.988 & 1.23 & 0.989 & 0.997 & 0.81 & 0.987 & 0.990 & 0.30 \\
\hline \begin{tabular}{|l|} 
Sun Life Everbright \\
Life Insurance
\end{tabular} & 0.594 & 0.897 & 51.01 & 0.807 & 0.943 & 16.85 & 0.736 & 0.951 & 29.21 \\
\hline AIA Life Insurance & 0.641 & 0.869 & 35.57 & 1.000 & 1.000 & 0.00 & 0.641 & 0.869 & 35.57 \\
\hline $\begin{array}{l}\text { Haier New York } \\
\text { Life Insurance }\end{array}$ & 0.856 & 0.886 & 3.50 & 0.977 & 0.960 & -1.74 & 0.876 & 0.922 & 5.25 \\
\hline $\begin{array}{l}\text { ING Capital Life } \\
\text { Insurance }\end{array}$ & 0.506 & 0.891 & 76.09 & 0.629 & 0.921 & 46.42 & 0.805 & 0.967 & 20.12 \\
\hline $\begin{array}{l}\text { Aviva-COFCO Life } \\
\text { Insurance }\end{array}$ & 0.539 & 0.862 & 59.93 & 0.777 & 0.930 & 19.69 & 0.693 & 0.927 & 33.77 \\
\hline \begin{tabular}{|l|} 
AEGON-CNOOC \\
Life Insurance \\
\end{tabular} & 0.696 & 0.898 & 29.02 & 0.780 & 0.952 & 22.05 & 0.892 & 0.942 & 5.61 \\
\hline \begin{tabular}{|l|} 
CIGNA\&CMC \\
Life Insurance \\
\end{tabular} & 0.973 & 0.988 & 1.54 & 0.973 & 0.990 & 1.75 & 1.000 & 0.998 & -0.20 \\
\hline \begin{tabular}{|l|}
$\begin{array}{l}\text { Nissay-SVA Life } \\
\text { Insurance }\end{array}$ \\
\end{tabular} & 0.993 & 0.991 & -0.20 & 0.993 & 0.996 & 0.30 & 1.000 & 0.995 & -0.50 \\
\hline Taiwan region & 0.891 & 0.846 & -5.05 & 0.917 & 0.936 & 2.07 & 0.968 & 0.898 & -7.23 \\
\hline Mainland China & 0.754 & 0.909 & 20.56 & 0.929 & 0.967 & 4.09 & 0.808 & 0.940 & 16.34 \\
\hline All & 0.814 & 0.881 & 8.23 & 0.923 & 0.953 & 3.25 & 0.879 & 0.921 & 4.78 \\
\hline
\end{tabular}

In Table 4, the average technical efficiency of life insurance industries in Taiwan and Mainland China is 0.886, Taiwan's average technical efficiency 0.846 is still lower than Mainland China's 0.909 , and the technical efficiency gap between them is $7.44 \%$. Of the firms, 9 life insurance companies have technical efficiency such as Central Life, Cathay, Fubon, Allianz, Global Life, ING, China Life Insurance, New China Life Insurance and China CMG Life Insurance, and the 5 having an inferior efficiency value are Taiwan's Prudential (0.608), MassMutual (0.688), Sinon (0.6), Hon Tai (0.599) and Prudential Finance (0.631).

\subsubsection{Technology gap ratio (TGR2 ${ }_{i}{ }^{*}$ )}

In Table 4, the average TGR of Taiwan's life insurance industry is 0.898 which is lower than that of Mainland China's 0.94 , namely the technical efficiency of Mainland China's life insurance industry has reached $94 \%$ of the whole life insurance industry's technical level. The technical level of Mainland China's life insurance industry is higher than that of Taiwan's. In Table 4, 9 life insurance companies' TGR has reached 1 as well, among which, the TGR of 6 companies in Taiwan is 1, while only 3 companies' TGR is 1 in Mainland China such as China Life Insurance, New China Life Insurance and China CMG Life Insurance, while Taiwan's Sinon (0.649) and Hon Tai (0.699) have a lower technical level.

\subsection{Comparison of business efficiency value before and after adjustment of variables}

4.5.1 Comparison between original efficiency value and technical efficiency value $\left(K_{i}-P T E^{*}\right)$ in Model II

Table 4 shows that the technical efficiency of Taiwan has increased to 0.936 from 0.917 (increase of $2.07 \%$ ), and that of Mainland China has risen to 0.967 from 0.929 (increase of 4.09\%). In Model II, 9 companies in Taiwan have an efficiency value, which is 2 less than the original number, but 5 companies have increased their technical efficiency value. Companies having a bigger increase are Prudential (increase of 29.17\%), Hon Tai (increase of 24.42\%) and MassMutual (increase of 22.05\%). Seven companies in Mainland China have an 
efficiency value in Model II, and 14 companies have increased their technical efficiency value. ING Capital Life Insurance has the biggest increase (increase of $46.42 \%$ ), and 3 companies' efficiency value are worse after the adjustment, among which CITIC-Prudential Life Insurance has the biggest decline (decrease of 8.88\%).

4.5.2 Comparison between original efficiency value and technical efficiency value $\left(\mathrm{M}_{i}-P T E^{*}\right)$ in Model II

The technical efficiency of life insurance industries in Taiwan and Mainland China is 0.881 , which is an increase of $8.23 \%$. The technical efficiency of Taiwan is 0.846 after the adjustment which is a decrease of $5.05 \%$. On the contrary, the technical efficiency of Mainland China in Model II is 0.909 which is an increase of 20.05\%. On average, the technical efficiency of Mainland China's life insurance industry is better than that in Taiwan under the same technical level. In Model II, 9 companies have technical efficiency, which is 5 less than the original number, while 26 companies have increased their technical efficiency value, 20 of which are from Mainland China. The companies having a bigger increase are Minsheng Life Insurance (increase of 132.25\%) and ING Capital Life Insurance (increase of 76.09\%) in Mainland China, but the efficiency value of Sinon in Taiwan turns worse after the adjustment (decrease of 24.24\%).

\subsubsection{Comparison between original efficiency value and TGR $\left(T G R_{i}^{*}\right)$ in Model II}

The TGR of Taiwan decreased to 0.898 from 0.968 after the adjustment (decrease of $7.23 \%$ ), while contrarily the TGR of Mainland China in Model II is 0.940 which is higher than the original 0.808 (increase of 16.34\%). Generally speaking, the technical level of Mainland China's life insurance industry is closer to the whole technical level than that of Taiwan's. In Model II, the number of companies whose TGR is 1 is 5 less than the original number, whereby there are 6 companies in Taiwan with a TGR of 1, and only 3 companies' TGR is 1 in Mainland China such as China Life Insurance, New China Life Insurance and China CMG Life Insurance, CIGNA\&CMC Life Insurance and Nissay-SVA Life Insurance whose TGR was 1 have changed after the adjustment. Companies having the biggest increase of TGR are Minsheng Life Insurance (increase of $122.59 \%$ ), Taiping Life Insurance (increase of 66.6\%) and CITIC-Prudential Life Insurance (increase of 62.15\%). And in Model II, the TGR of Hon Tai (decrease of $28.67 \%$ ) and Singfor (decrease of $22.51 \%$ ) becomes worse.

\section{Conclusions}

The author use the original data for analysis based on "BCC input orientation". First, on the technical efficiency of various group frontiers, the average technical efficiency of Taiwan's industry shows a continuous decline, while the average efficiency of Mainland China's is increasing continuously. As for the Metafrontier technical efficiency, the technical efficiency of Taiwan's industry is apparently higher than that of Mainland China's, but the production technology gap between both sides shows a reducing trend, and based on the Wilcoxon rank-sum test, there is actually a difference in the business efficiency between life insurance industries in Taiwan and Mainland China. As for the TGR, Taiwan is closer to the whole technical level than Mainland China, and Taiping Life Insurance and Minsheng Life Insurance have a lower technical level.

Tobit regression analysis is also applied, and the impact of environment variables on the input slack variables is separated so as to be the basis of adjusting the input variables. The special point of this study is that the life insurance industries in Taiwan and Mainland China select the same environment variables (Model II) for adjustment. In Model II, it is found that the "region" and "listed and over-the-counter company" impact the input slack variables most among six environment variables.

After the environment variables are considered respectively, the technical efficiency value is estimated again 
based on the adjusted input data and original output data. According to the technical efficiency of various group frontiers in Model II, both Taiwan and Mainland China have increased their efficiency value, but Mainland China shows a large increase. Second, under the metafrontier technical efficiency, the number of life insurance companies having technical efficiency in Model II is increased to 9; Taiwan's life insurance industry has 4 companies left which are Central Life, Fubon, Allianz and Aegon, while Mainland China has only 3 companies left which are China Life Insurance, New China Life Insurance and China CMG Life Insurance. Finally, the Wilcoxon rank-sum test showed that there is no difference between the efficiency values of life insurance companies in Taiwan and Mainland China. It may be that the environment variables selected in this paper have adjusted the life insurance industries in Taiwan and Mainland China. Although the technical efficiency values of both sides have apparently changed the difference between efficiency values is not large, and thus there is a significant difference between the life insurance industries in Taiwan and Mainland China. On the TGR, the technical efficiency level of Mainland China is apparently higher than that of Taiwan.

This study finally carries out a non-parametric testing of the hypothesis aiming at various groups after adjustment and the whole efficiency value, for whether there is any relativity and obvious relation, Kendall's tau test and Wilcoxon sign rank test are used for the relativity test and the otherness test, respectively. When measuring the relativity result before and after adjustment, it is found that under the $\alpha=0.01$ level of significance, the technical efficiency of each group, Metafrontier technical efficiency, and TGR have strong relativity before and after the adjustment. Furthermore, through measuring whether there is a significant difference before and after adjustment, it is found that under the technical efficiency value of each group and common technical efficiency value, the technical efficiency of Mainland China's life insurance industry under the $\alpha=0.05$ level of significance has a very big difference before and after adjustment. On TGR, the efficiency value of both Taiwan and Mainland China under the $\alpha=0.05$ level of significance has a very big difference.

Before considering the environment variables, the integrated business performance of Taiwan's life insurance industry is in general apparently higher than that of Mainland China's life insurance industry. However, based on the adjustment (Model II) result of life insurance industries in Taiwan and Mainland China, most life insurance companies' efficiency value shows a big change. However, for each group, if the life insurance companies in Mainland China haven't adjusted and analyzed the environment variables and only used the original technical efficiency, then an apparent underestimation will occur, and compared with Mainland China, Taiwan is overestimated. As shown, Mainland China has fully opened its life insurance market. After entering WTO, many foreign life insurance companies have been set up and the insurance laws have been amended greatly. Thus, the production technology of the whole life insurance industry in Mainland China has developed even faster than the whole life insurance industry in Taiwan.

\section{References:}

Coelli. T. J. (1996). A guide to DEAP2.1: A data envelopment analysis computer program. CEAP working paper.

D.S. Prasada Rao. (2006). Metafrontier frameworks for the study of firm-level efficiencies and technology gaps. 2006 Productivity and Efficiency Seminar Taipei, 10th March, 2006.

D.S. Prasada Rao, et al. (2003). Metafrontier functions for the study of inter-regional productivity differences. Center for Efficiency and Productivity Analysis. The University of Queensland, Brisbane Australia, Working Paper Series NO. 01/2003.

Fried. H. O., S. S. Schmidt \& S. Yaisawarng. (1999). Incorporating the operating environment into a nonparametic measure of technical efficiency. The Journal of Productivity Analysis, 12, 249-267.

HU Jin-li, LI Chin-yuan \& CHU Wei-kai. (2007). Operating environment-adjusted nationwide bank efficiency in China. The Journal of Science Project, 1-30.

(Edited by Rudy and Chris) 